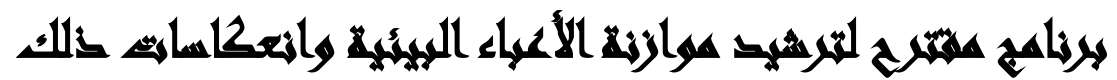

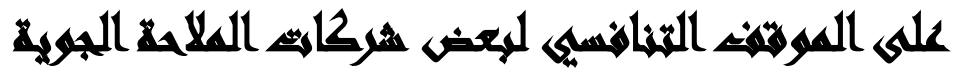

[19]

طارق عبد العال حماد(')- جمال سعد خطاب(')- عبد الفتاح عبد الرازق السيد(ץمد فريد

() كلية التجارة، جامعة عين شمس r) شركة الملاحة الجوية، القابضة للمطارات

\section{المستخلي}

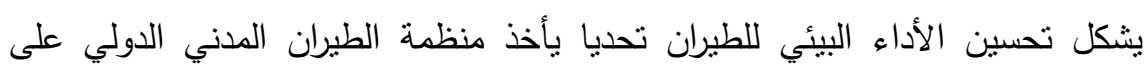

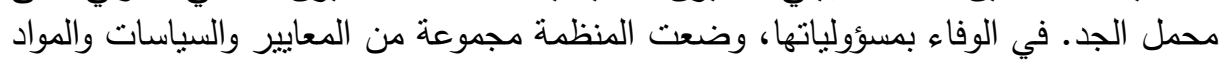

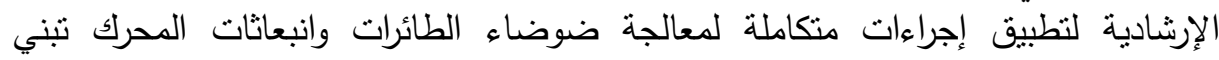

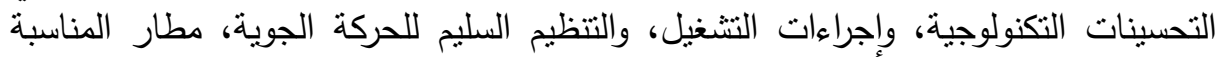

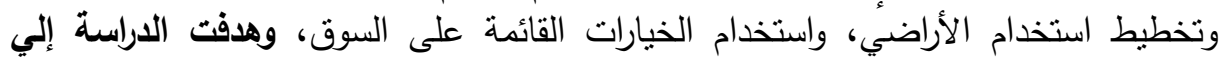

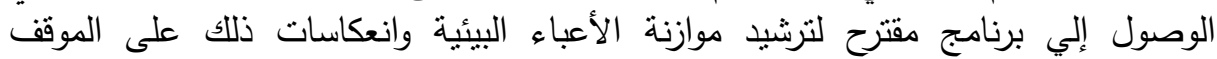

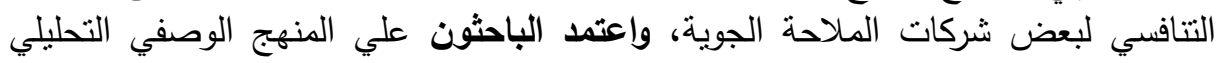

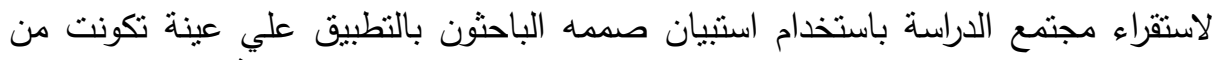

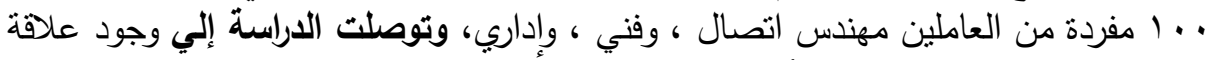

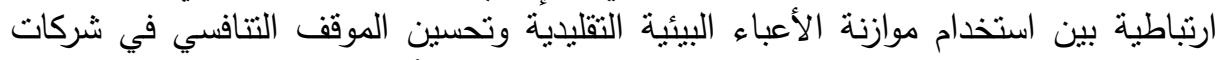

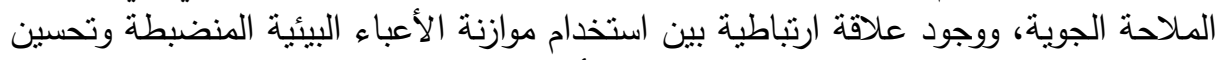

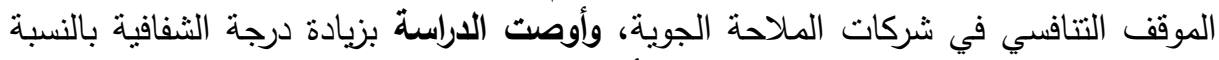

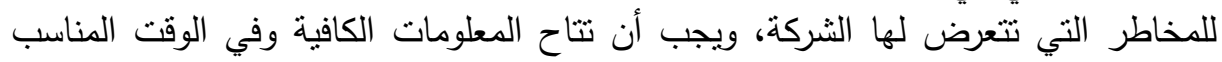
للمتعاملين معها لضمان ترشيد تللك الأعباء لاعم موقف الثركة.

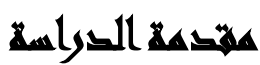

لقد بدأت قضايا البيئة نطرح نفسها في السنوات الأخيرة بشكل أدى إلى بذل العديد من الجهود لعلاج مشكلاتها، مما أثنار العديد من التساؤلات حول علاقة هذه المشكلات البيئية بالأنشطة الاقتصادية والتتموية، لمعرفة مدى تأثثرها على استمرار عمليات التتمية خصوصا في شركات الملاحة الجوية ، ويوجد الآن ما يعرف المحاسبة البيئية آو تقييم الأثار البيئية،

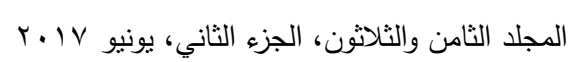


متمثلة في قياس التكاليف والمنافع البيئية الناتجة عنها، كما أصبحت من الأمور الحيوية والهامة لمتخذي القرارات على كافة المستويات، مستوى المنشأة والقطاع ، ولكن تكمن الصعوبة في قياس تلك التكاليف والمنافع من أن معظم الأثار البيئية للمنشأة تعتبر غير ولثي مباشرة، بمعنى أنه لا يوجد سعر سوق لحسابها، لهذا دائما ما نستخدم الطرق غير النان المباشرة

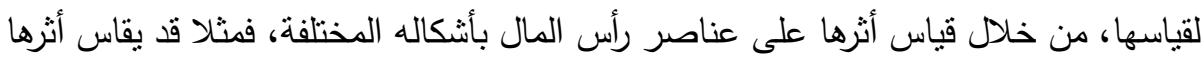

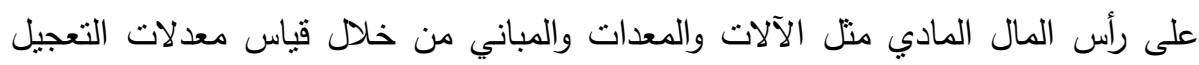
بإهلاكه عن العمر الافتراضي المقدر له، وقد يقاس أثرها علي رأس المال البشرى من خلال

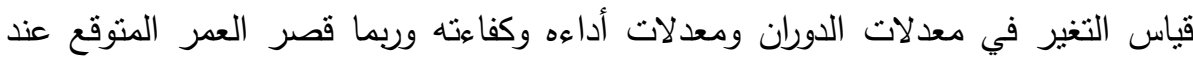

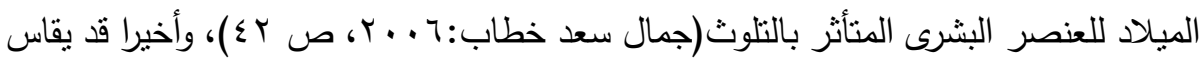

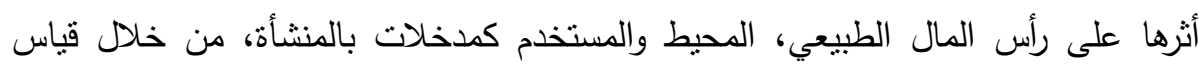

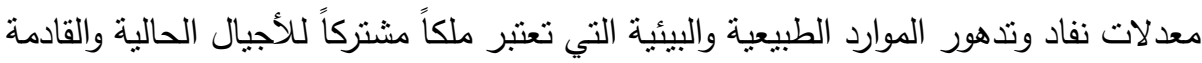

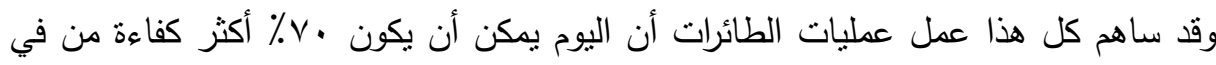

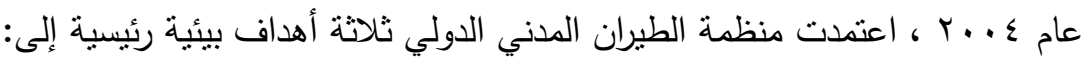
- الحد من أو تقليل عدد الأشخاص المتضررين من ضوضاء اعنداء الطائرات كبيرة . - تقييد أو الحد من تأثير انبعاثات الطيران على نوعية الهواء المحلي.

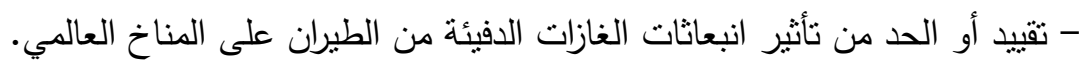

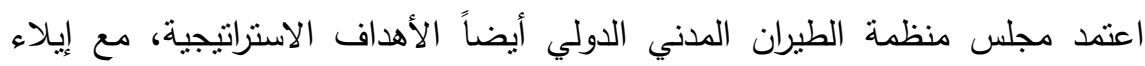

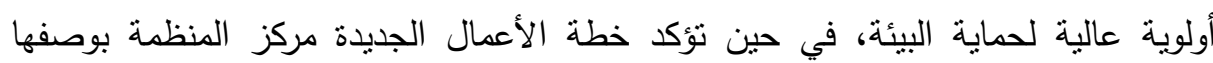

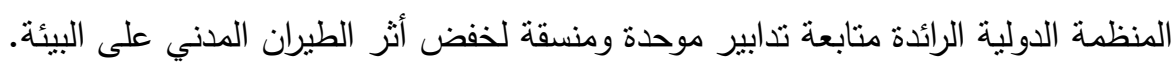

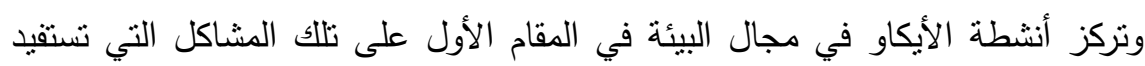

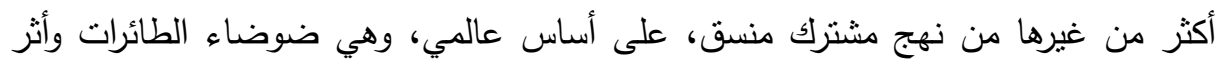
انبعاثات محركات الطائرات، ويجري معظم هذا العمل من خلال لجنة مجلس الأيكاو بشأن عأن حماية البيئة الطيران (لجنة حماية البيئة)، الذي يتألف من الأعضاء والمراقبين من الدول 
والمنظمات الحكومية الدولية والمنظمات غير الحكومية التي تمثل صناعة الطيران والمصالح

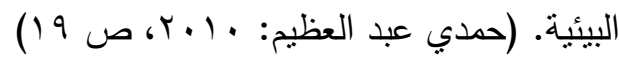

وتتم مراجعة البيان الموحد لاستمرار السياسات والممارسات المتعلقة بحماية البيئة وتحديثها من قبل المجلس كل ثلاث سنوات لاعتمادها من قبل الجمعية العمومية للأيكاو

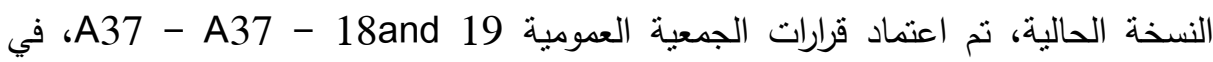

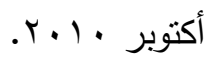

تحتفظ الأيكاو علاقات وثيقة مع هيئات صنع السياسة الأمم المتحدة الأخرى التي

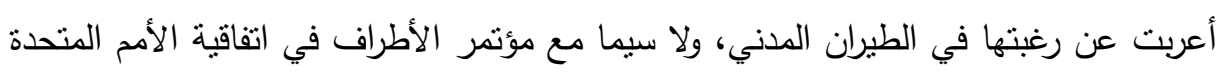

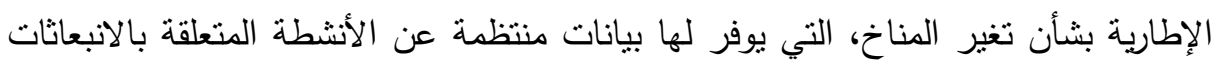

ولتحديد الاستراتيجية المالية الخاصة بشركات الملاحة الجوية من الناحية البيئية لابد من الوضع في الاعتبار أن الأهداف الاستراتيجية لابد أن تكون محددة وواضحة وتحقق الإدارة

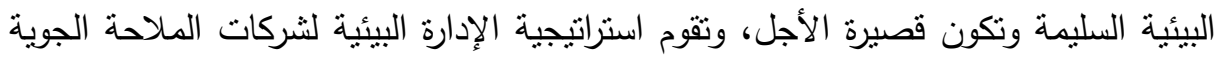

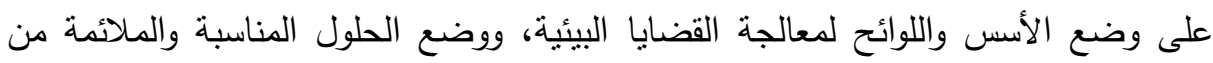
أجل عمليات التتمية المستدامة مع المتابعة المستمرة للتأكد من الاستفادة من ترشيد موازنة الأعباء البيئية في الموقف النتافسي لثركات الملاحة الجوية. تحقيق المعدلات المطلوبة حسب النتريعات والقوانين العالمية الملزمة لذلك، وهذا يستلزم إجراء عمليات رصد ميداني حسب الخطة الزمنية المعلومة والمحدة من أجل تحديد مدى ملائمة الخطة لخطوات سير العمل وفى هذا الصدد فإنه يمكن تلخيص معالم استراتيجية

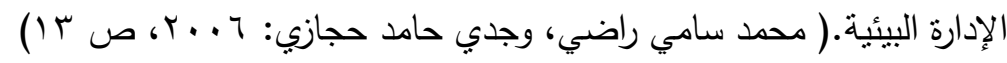
تحسين الأداء البيئي للطيران يشكل تحديا يأخذ منظمة الطيران المدني الدولي على هلى

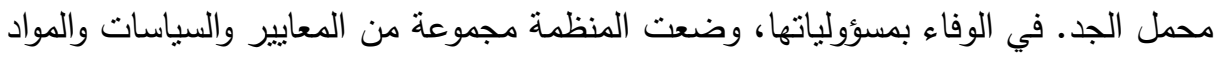
الإرشادية لنطبيق إجراءات متكاملة لمعالجة ضوضاء الطائرات وانبعاثات المحرك تبني فئي التحسينات التكنولوجية، وإجراءات التشغيل، والتتظيم السليم للحركة الجوية، مطار المناسبة

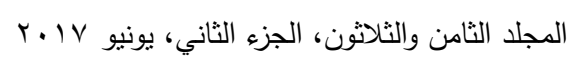


وتخطيط استخدام الأراضي، واستخدام الخيارات القائمة على السوق.( وديع محمد عدنان:

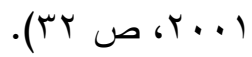

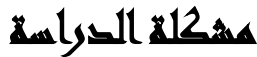

إن آمال قياس الأثار البيئية للمنشآت، بآثارها المتعددة على رأس المال بأشكاله المختلفة،

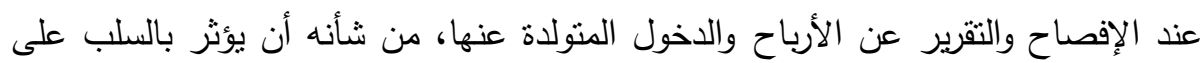

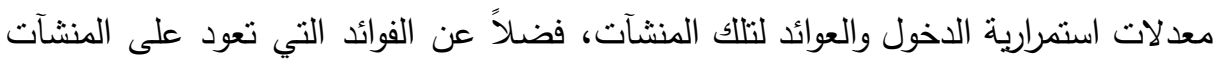

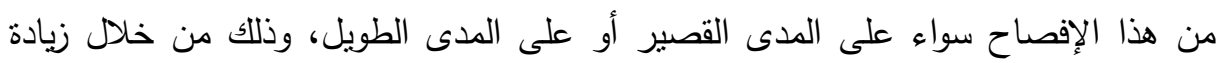

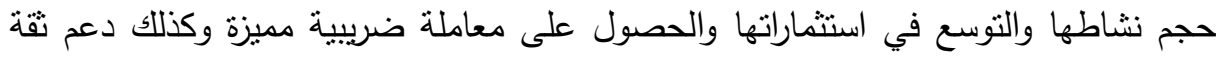

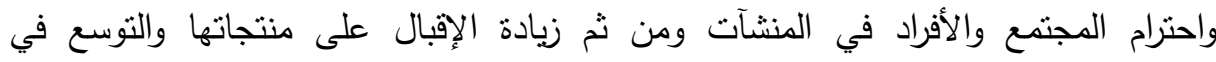
استثماراتها، الأمر الذى ينعكس أثره في النهاية على نتيجة نشاطها ومركزها المالي، وبينت دراسة "Demery, 2014" التي أكدت على ضرورة قياس وتحليل تكاليف الأداء البيئي

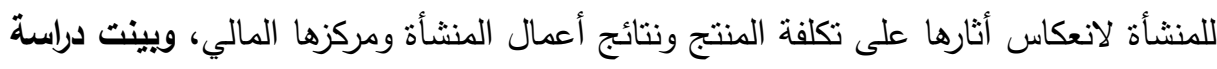
ماهر عبد الوهاب سيف قطب 9 . . ب أن المواصفات العالمية لنظم الإدارة البيئية خطوة مهمة في تصميم وتحسين نظم الإدارة البيئية بالثركات الصناعية والتي تحصل علي شهادة مطابقة نظم الإدارة البيئية( EMS ) وطبقاً إحدى هذه المواصفات، فإن ذللك يكون دليلاً علي الجهد الذي تبذله هذه الثركات لمنع التلوث باستخدام التكنولوجيات المتاحة لديها وكذللك علي قدرتها علي الإدارة الجيدة والحد من تأثيراتها البيئية والتحسن البيئي المستمر، وناقث الباحث التوازن بين البيئة والتتمية وذلك عن طريق استخدام تقييم الأثر البيئي (Environmental EIA) Impact Assessment لمشروعات التتمية بما يسمى التوافق البيئي في ظل سياسات بيئية ترنكز علي استراتيجية

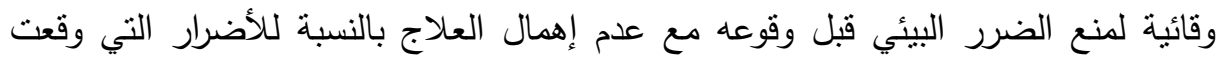

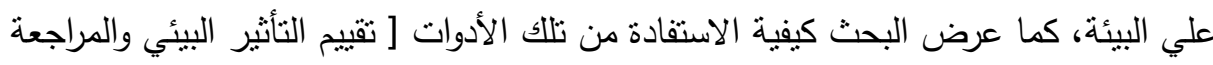
البيئية ] في تقديم الدعم العلمي اللازم لمتخذي القرارات البيئية حماية البيئة وصوناً للموارد 
الطبيعية، وتناولت دراسة محمد نادر عثمان ه. . . تأثير المتغيرات الحديثة على تقارير

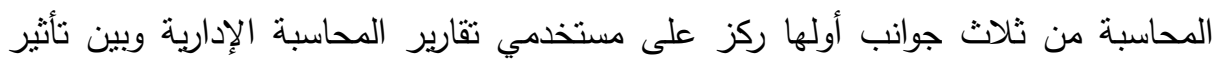
متغيرات بيئية التصنيع الحديثة، واستحداث لعملاء جدد من مستخدمي نقارير المحاسبة الإدارية داخل المنظمة متمثلين بكل أفراد المنظمة وبكل المستويات، أما الجانب الثاني فقدات ناقث أثز متغيرات بيئة التصنيع الحديثة على محتوى أو مضمون تقارير المحاسبة الإدارية

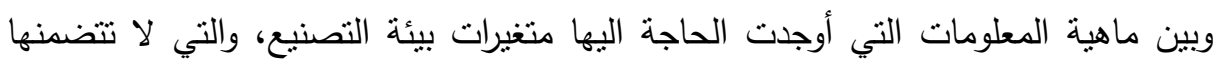
ثقارير المحاسبة الإدارية، كما تتاول في الجانب الثالث أثز بيئة التصنيع الحديثة على دورية تقارير المحاسبة الإدارية، ومن الأهداف الأساسية للمراقبة الجوية فئة الجانية • منع الحوادث بين (الطائرات والأخرى - بين الطائرات والعوائق الجوية). • ت نسهيل وتشهيل الحركة الجوية. • تحقيق عامل الأمان بين الطائرات. • الإثراف والمسئولية عن جميع نواحي المطار من إنارة وإسعاف وإطفاء.

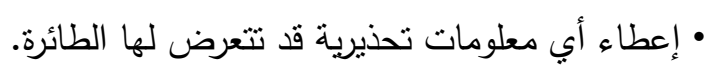

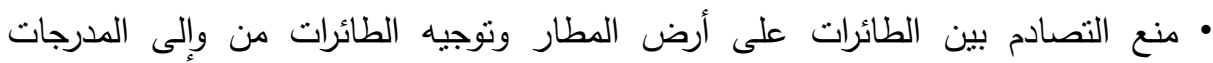

$$
\text { والمواقف. }
$$

$$
\text { • المحافظة على حركة الطائرات بشكل سريع منتظم وآمن. }
$$

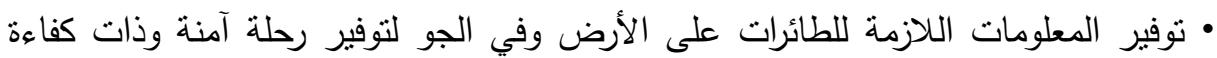
عالية. • إبلاغ الجهات اللازمة في حال احتباج الطائرة إلى فرق البحث والإنقاذ أو في حال الحوادث

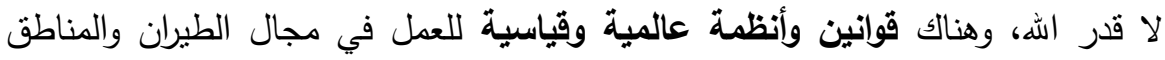
البالغة الحساسية والتي لا بد من العمل فيها بشكل جدي والالتزام بالقوانين واللغة الخاصة بالطبران بحيث لا يكون هنالك مجال للخطأ أو سوء الفهر بين الطيار والمراقب الجوي بهن

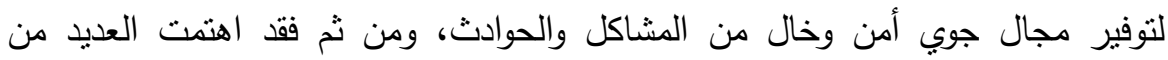

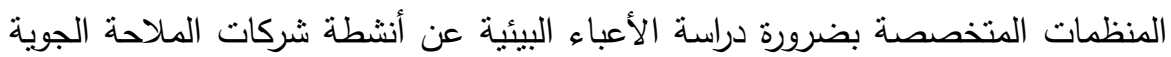

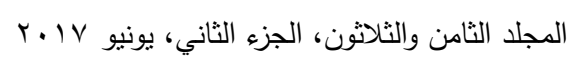


والتقرير عن التكاليف والعوائد المترتبة على تلك الأنشطة، وذلك لأن الإفصاح عن الأداء البيئي للمنشآت هام لتلبية الاحتياجات المتزايدة لمستخدمي القوائم المالية المتعلقة بشركات

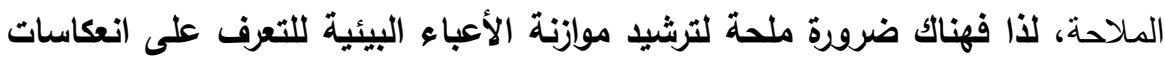
ذلك على الموقف التنافسي لشركات الملاحة الجوية.

\section{هروضر التواسم}

1- توجد علاقة جوهرية بين استخدام موازنة الأعباء البيئية التقليدية وتحسين الموقف التتافسي

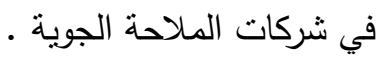
r- توجد علاقة جوهرية بين استخدام موازنة الأعباء البيئية المنضبطة وتحسين الموقف التنافسي في شركات الملاحة الجوية . r- توجد علاقة جوهرية بين دور الدولة في تدعيم قدرات شركات الملاحة الجوية وتحسين الموقف التتافسي لها.

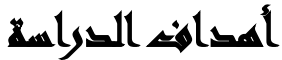

تهذف هذه الاراسة إلى تحقيق ما يلي:

- التعرف علي العلاقة بين استخدام موازنة الأعباء البيئية التقليدية وتحسين الموقف التتافسي

$$
\text { في شركات الملاحة الجوية . }
$$

- التعرف علي العلاقة بين استخدام موازنة الأعباء البيئية المنضبطة وتحسين الموقف لـن

$$
\text { النتافسي في شركات الملاحة الجوية. }
$$

- التعرف علي العلاقة بين دور الدولة في تدعيم قدرات شركات الملاحة الجوية وتحسين

$$
\text { الموقف التتافسي لها. }
$$

\section{أهمه التواسمة}

تتجلى أهمية البحث في إيجاد إطار مقترح لترشيد موازنة الأعباء البيئية وانعكاسات ذلك

على الموقف التنافسي لثركات الملاحة الجوية من خلال: 
- التأكيد على جعل الاعتبارات البيئية معلومة ومحددة لاى القائمين على إدارة شركات الملاحة الجوية جنباً إلى جنب مع الاعنبارات الاقتصادية، وذلك من خلال إطار إجرائي ومؤسسي فعال لنظم الإدارة البيئية.

- إتاحة خطة عمل قابلة للنطبيق لنظم إدارة بيئية مبنية على تطوير إطار عمل قائم فعلاً

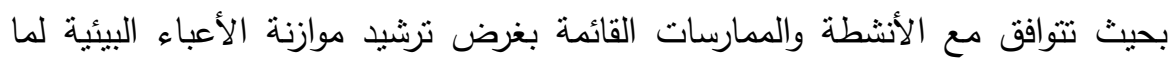
لذلك من أثز على الموقف التتافسي لنشركات الملاحة الجوية.

\section{مسطلحاهي التوراسمة}

ا-المحاسبة البيئية: وهو مصطلح يقابله العديد من المرادفات مثل محاسبة دورة الحياة

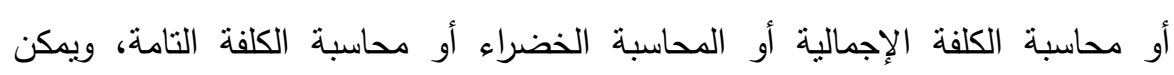
مضمونها في إنها نشاط خدمي ينم تطويعه لتعزيز المبادرات والسياسات البيئية بتضمينها الكلف والمنافع البيئية التي تسفر عن ممارسة المنشآت لأنشطتها. ( Emblemsvag) and Bras, 2001, p.5

r-التكاليف البيئية: إن الكلف البيئية تمثل النفقات البيئية المتضمنة كلف الخطوات المتخذة لتفادي وخفض وإصلاح الدمار البيئي الناجم عن ممارسة المنشأة لأنشطتها، أو للمحافظة على الموارد المتجددة وغير المتجددة وتتسع هذه الكلف لتشمل الإنفاق على تجنب النفايات والتخلص منها، والمحافظة على المياه السطحية والجوفية والمحافظة على نوعية

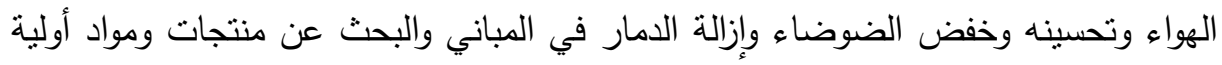
وعمليات إنتاجية أكثر صداقة للبيئة، ويمكن أن تشمل التكاليف البيئية كلف الإجراءات

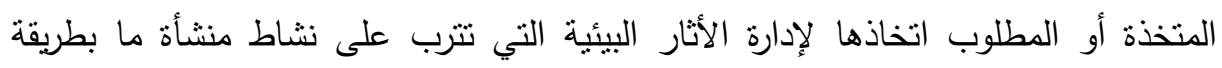
مسؤولة بيئياً، فضلا عن الكلف الأخرى التي تتطلبها الأهداف والمتطلبات البيئية للمنشأة) (united Nations, 1999, p.13 
r- موازنة الأعباء البيئية: يعرفها الباحث في الدراسة بأنها التكاليف التي تضعها الثركة ضدن الميزانية السنوية لها، وتكون خاصة بالسياسات والاجراءات البيئية التي

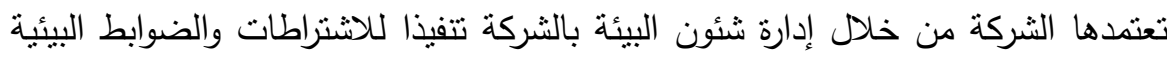
المحلية والدولية المتعلقة بشركات الملاحة الجوية.

\section{مشوض القواسمة}

الحد الجغرافي: الثركة الوطنية لخدمات الملاحة الجوية وهي إحدى الثركات التابعة لوزارة الطبران المدني المصرية. الحد البشري: عينة من .1 مفردة شملت الآتي: (المهندسين، ومراقبي الجودة، والمحاسبين، وضابط الاتصالات، والإداريين.)

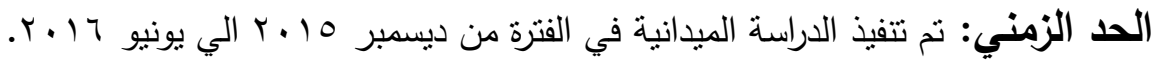

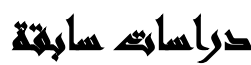

ا - دراسـة 2012 : Robert Gale والتي أنشارت إلى عدم تركيز نظم المعلومات على توفير معلومات للفحص البيئي للإدارة العليا، وبالنسبة للعديد من الموظفين وقد تكون عدم الحاجة إلى معلومات داخلية بنفس درجة القوة، ويرجع ذلك لعدم توفير تقييم دقيق لقدرة الثركة على توفير المعلومات المالية البيئية.

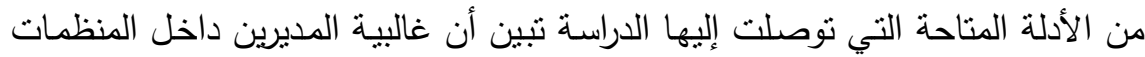
ليس لديهم اهتمام بالبيئة والتكاليف المرتبطة بها على الرغم من أن بعض المدئه المديرين والمحاسبين

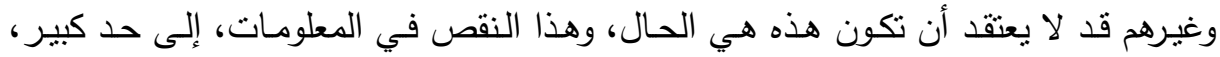

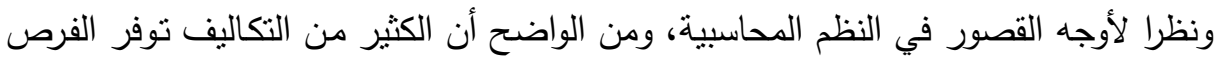
التى قد ضاعت بسبب من عدم وجود معلومات عن التكاليف البيئية. 
يرى الباحث أن الاهتمام بالمعلومات البيئية عند المديرين يرجع إلى سياسات الثركات

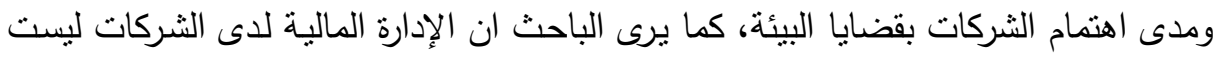
على علم تام بصعوبة فصل التكاليف البيئية مما يؤدى إلى نتائج مضللة في التقارير المالية

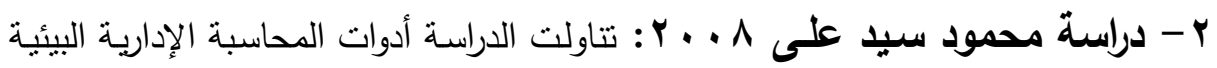
وإرتباطها بنظم الإدارة البيئية، ومدى الإرتباط ما بين السباسات التجارية والبيئية حيث تم

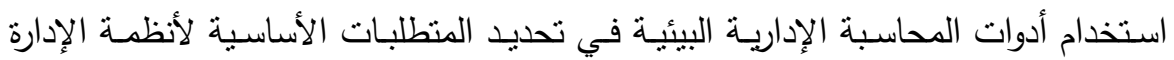
البيئية ايزو . . ـ ا، منل تحديد المظاهر والتأثيرات البيئية وقياس مدى التقدم في سياسة الثـركة ووضـع الخطط البيئية مسن أهداف ومستهدفات وقياس الأداء البيئي بالمؤشـرات

$$
\text { وحساب الكفاءة الاقتصادية. }
$$

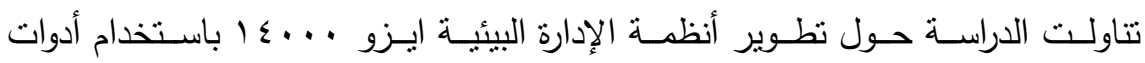
المحاسبة الإدارية البيئية، مثل المحاسبة عن تدفقات المواد والطاقة (حسابات التوازن البيئي)

$$
\text { والتكاليف البيئية ومؤشرات الأداء البيئي. }
$$

ب - دراسـة 2006 Graciela María Scavone : تتاولت هذه الدراسـة حول تركيز على كيفية إعداد التقارير الداخلية لتطبيق أساليب الإنتاج الأنظف من خلال الإدارة البيئية

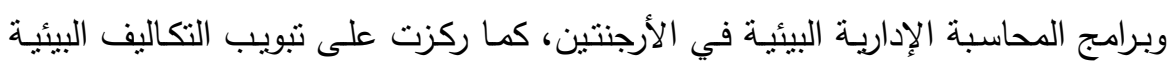
والفوائد البيئية من التبويب، والآليات المعتمدة لقياس التكاليف البيئية ومدى استمرار الإدارة

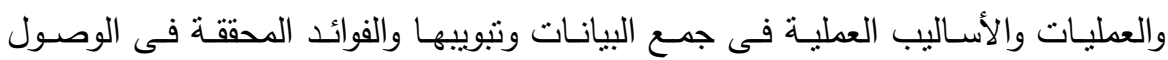

$$
\text { للقياس السليم للتكاليف البيئية. }
$$

تبين أن هناك حالات لا تتوفر فيها المعلومات البيئية بسبب نظم المعلومات المحاسبية

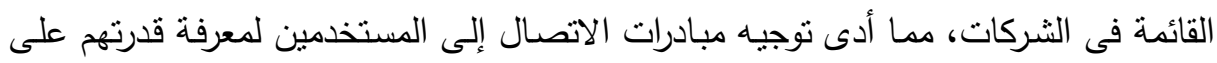

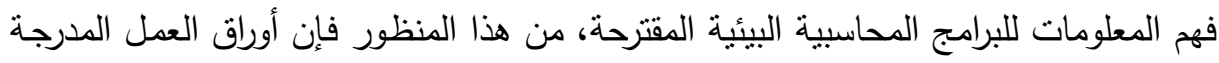

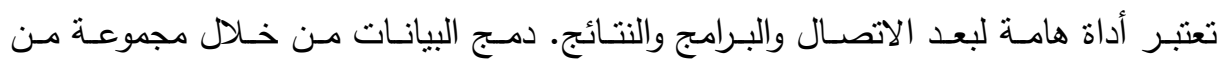
المؤشرات وفقا للنظم البيئية سجل النتائج المتوازن المنهجية قد يوفر معلومات هامة لصانعي القرار وتضيف قيمة حقيقية للتتمية المستدامة.

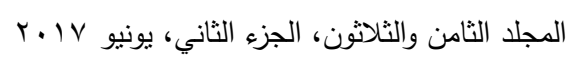




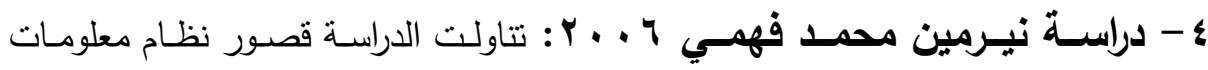
المحاسبة الإدارية في مساندة الإدارة للقيام بوظائفها حيث أنه مازال يعتمد ذات الأساليب

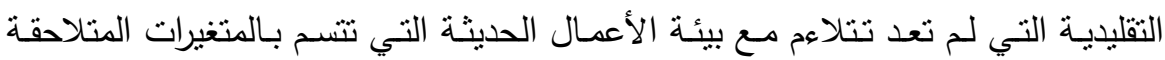

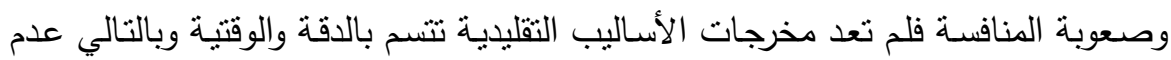
القدرة على اتخاذ القرار المناسب في الوقت المناسب. استهدفت الدراسة تطوير الأساليب التقليدية منها أسلوب استخدام التكلفة المستهدفة لزيادة

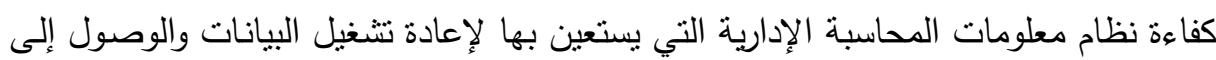
مخرجات تتسم بالتفصيل والثمول والدقة والوقتنية. يرى الباحث أن تطوير نظام معلومات المحاسبة الإدارية يجب أن يأخذ في الاعتبار

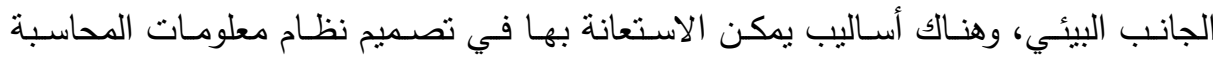
الإدارية الذي يوفر المعلومات البيئية لمتخذي القرارات على كافة المستويات داخل المنظمة.

\section{إلطار نظيه}

مفهوم وأهميـة الموازتـات التقديريـة: الموازنـات التقديريـة تعتبر عنصر من العناصر الحديثة في النظام المحاسبي برغم من أن فكرة استخدامها ليست حديثة فقد استخدمت منذ فئن الزمن البعيد بهدف إيجاد التوازن بين الإنفاق الحكومي والموارد العامة ولكن بعد التطورات

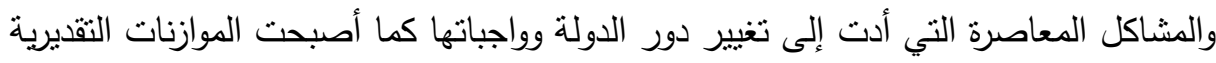

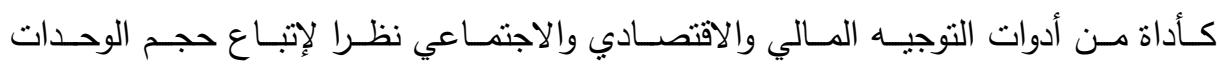

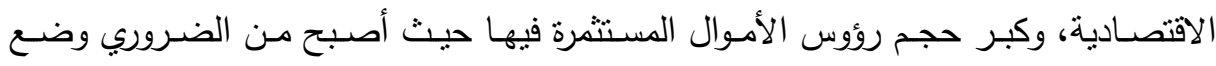
أسلوب للعمل لتحقيق أفضل النتائج والأهداف المرجوة. أولاً: - تعريف الموازنات التقديرية، خصائصها وأهميتها: 1-تعريف الموازتـات التقديريـة: الرقابـة والتخطيط يعدان وجهان لعملة واحدة وللقيام بهاتين

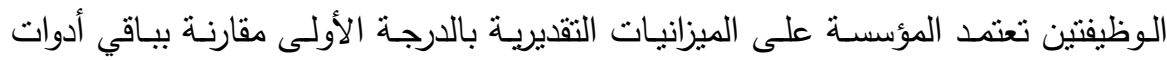

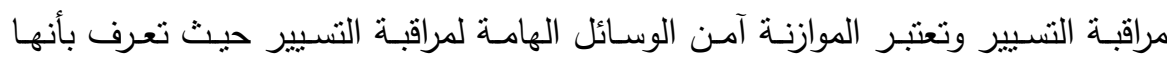


التعبير عن مخنلف القرارات والأعمال المستقبلية بمعنى أنه لا يمكن مناقتــة التخطيط

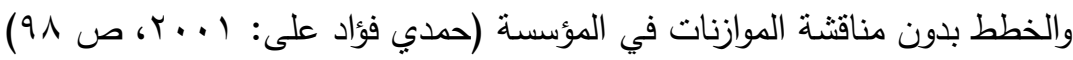

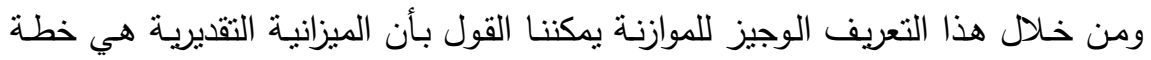

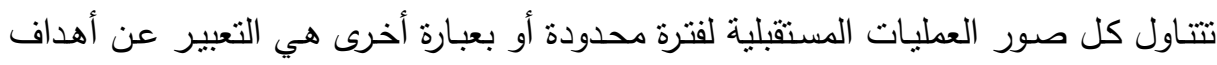

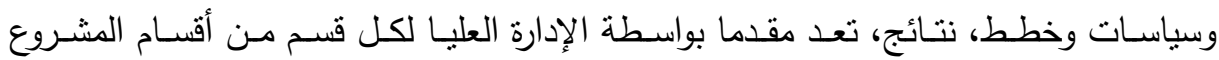

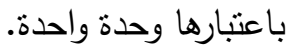
وتتكون الميزانية التقديرية الموحدة للمشروع من عدة ميزانيات فرعية لكل قسم، وتتكون

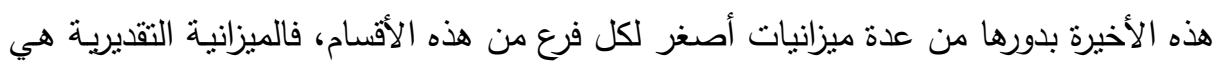
بمثابة أداة تستخدم في التعبير عن هدف معين تسعى إلى تحقيقه إدارة المؤسسة. وقد يحدث العكس لذلك كان من الضروري متابعة تتفيذ لإجراء تعديلات معينة تكفل نجاح الخطة الموضوعة، بل قد يتطلب الأمر إدخال تعديل شامل على البرنامج المرسوم. (Wilsmore ,A ,wcc;1999, p 23 ) حيث يعرفها Horngren بأنها: تعبير كمي لخطة الأعمال تساعد على تحقيق التتسيق

كمـا تعرف بأنها وسيلة من وسـائل التخطيط والرقابـة والتتسيق بين مختلف نشـاطات المنشأة، ويعتبرها البعض بمثابة برنامج زمني متم بموجبه تحديد مختلف النشاطات المستقبلية

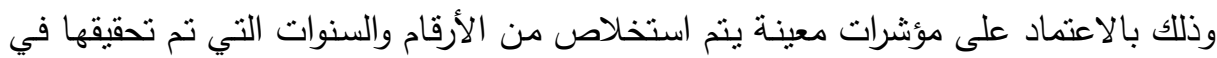

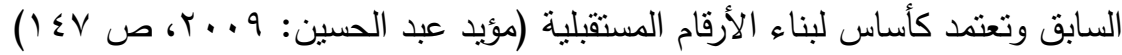
وتعرف كذللك بأنها تكوين الخطط الخاصـة لفترة زمنية مقبلة مـع التعبير عنها بأرقام قد

تكون في شكل مبالغ مالية، أو ساعات عمل أو وحدات إنتاج أو أي مقياس رقمي آخر .

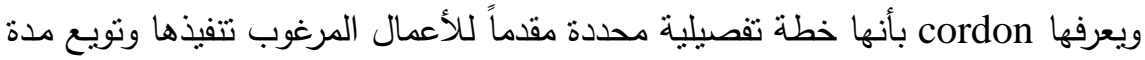
الخطة على جميع المسؤولين حتى تكون مرشداً لهم في تصرفاتهم وحتى يمكن استخدامها

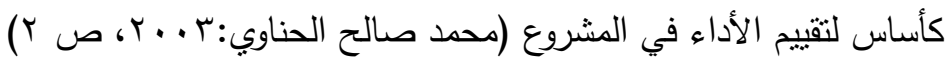

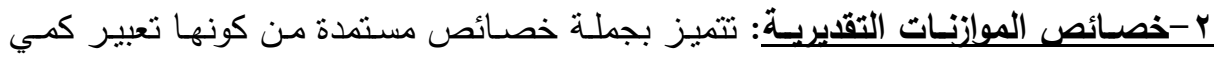
ومالي لبرنامج عمل محدد. 


\section{ويمكن تلخيصها فيما يلي:}

- تعبير كمي: فتحقيق البرامج القصيرة الأجل يستدعى ترجمة الأهداف إلى كميات، وكذا

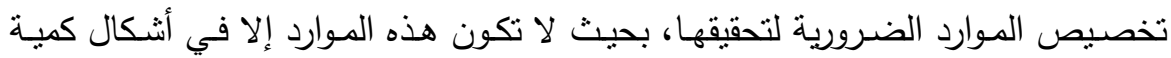

ومالية.

- تحـد فـي شـكل برنـامج عمـل: الموازنـة التقديريـة لا تعد فقط تقديراً للأهداف والمـوارد

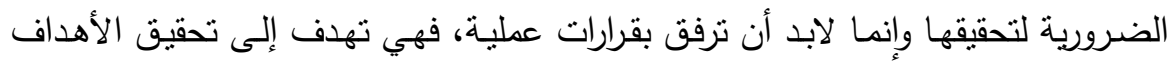
المسطرة وليس معرفة وتتبؤ المستقبل من أجل المعرفة فقط.

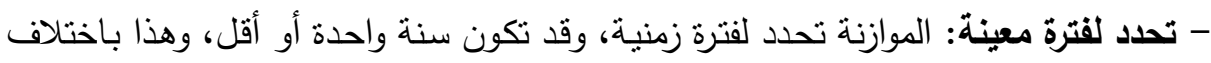
نشاط المؤسسة وأهدفها. حيث تعد الموازنة ترجمة كمية برنامج العمل المحدد، والتي هي جزء تتفيذي للمخططات

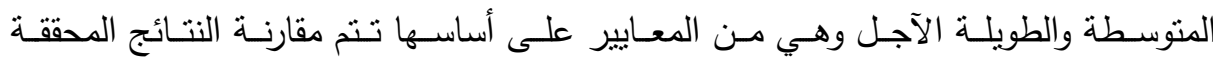
واستخلاص الفروقات، ومن اتخاذ التدابير الملائمة لتحسين التعبير • ومن الأخر يمكن القول بأن الميزانية التقديرية نعتبر أداة للتخطيط والتتسيق والمراقبة كما أنها

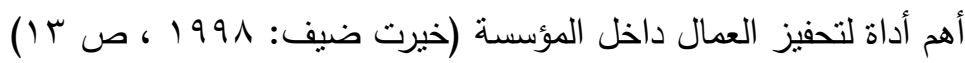
ب-أهمية الموازنة التقديرية:

تظهر أهمية الموازنة التقديرية في المرحلة الأولى من خلال أهدافها التي تتمتع بدراسة

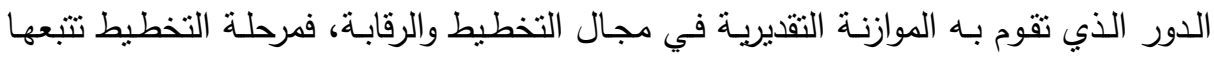
مرحلة التتسيق أي التتسيق بين الأجهزة الفنية والمالية وتوجيه الإمكانيات المتاحة، وذلك من فن فيه

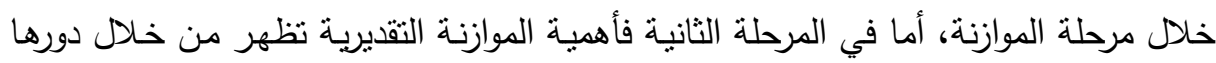
في إعداد وثائق التسيير المالي على الصعيد المستقبلي مثل: جدول حسابات النتائج التقديري من فئه الميزانية التقديرية.

وذلك على أساس أن الموازنة التقديرية هي من المخطط العام، وهي تتفيذ برنامج عاملين وبالتالي فهي تساعد المسؤولين الإداريين في عملية صنع القرار وذللك على جميع المستويات

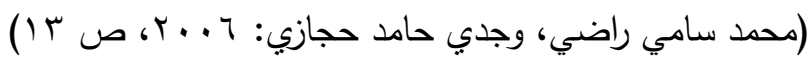




\section{ثانياً: -وظائف الميزانية التقديرية ومبادئها}

1-وظائف الميزانبة التقبرية: نظراً لأن الموازنات التقديرية تمثل خطة كمية وقيمية تتضمن الأهداف المختلفة للمنشآت، كما تحتوي على مجموعة من الأنشطة اللازمة لتحقيق الأهداف والمفاضلة بين البدائل المختلفة وتقييمها واختيار البدائل أو مجموعة من البدائل المناسبة فئن إنان

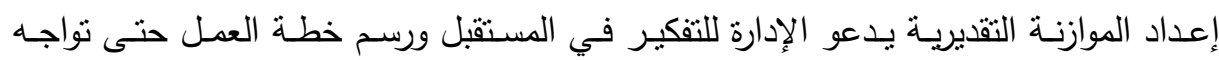

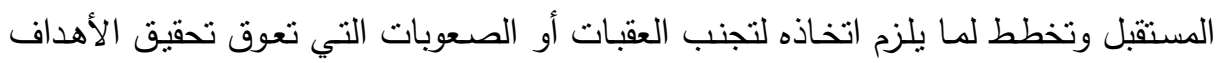
المرجوة، وتعد الموازنة إدارية إذ أنها تناعد إدارة المشروع في أداء وتحقيق الوظائف الإدارية الرئيسية الآتية:

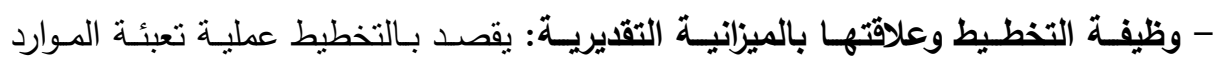
الاقتصادية المتاحة والمحتملة وخلال فترة مستقبلية محددة بما يضمن استتمارها استتمارا كاملاً وأمتل ويستتد المخطط في عملية التخطيط على قاعدة البيانات والمعلومات المتوفرة

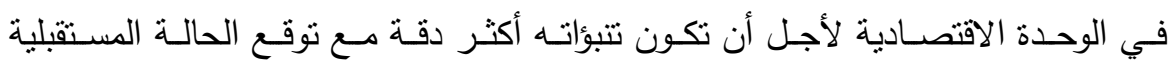

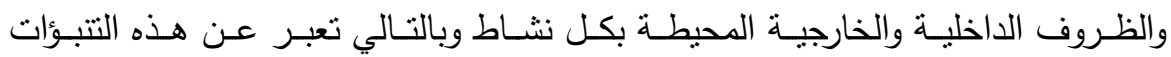
والتوقعات المستقبلية بصورة رقمية، وتتمثنل وظيفة التخطبط في وضـع الأهداف وإعداد

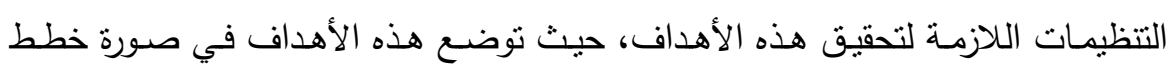

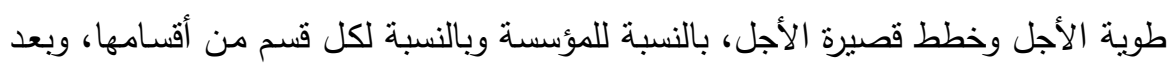
أن ينم التخطيط يصبح من الضـروري تتظيم عوامل الإنتاج تتظيمياً يؤدي إلى تحقيق الأهداف المسطرة. ويتطلب التخطيط تنفيذ ثلاث خطوات رئيسية هي:

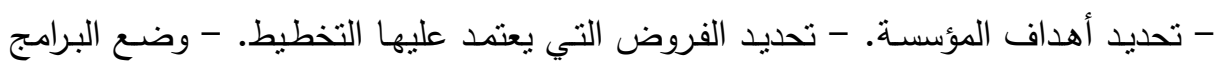
والسياسات.

- وظيفـة التنسـيق وعلاقتهـا بالميزانيـة التقديريـة: يمثل التتسبق العملية التي بموجبها يتت

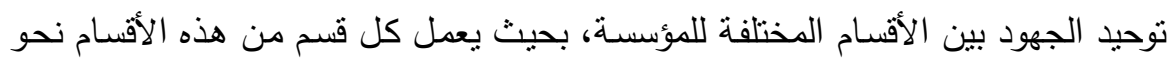

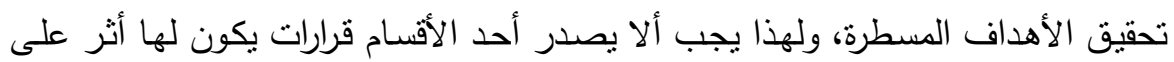

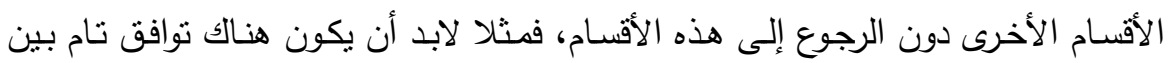

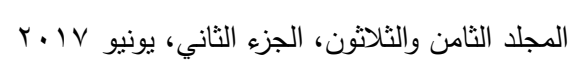


المبيعات والإنتاج بحيث لا ينبغي أن ترسم إدارة المبيعات سياسة بيعية لكميات تزيد عن

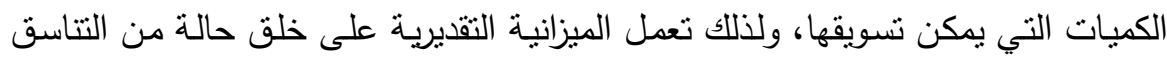

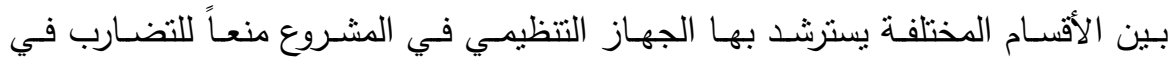

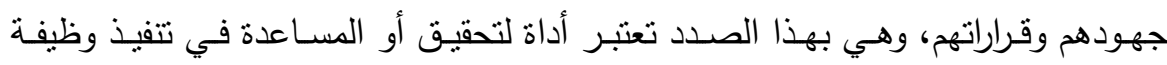
النتسيق التي تمارسها الإدارة(خبراء الثركة العربية المتحدة للتدريب والاستنمارات الإدارية:

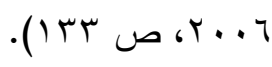
- وظيفـة الاتصـال وعلاقتهـا بالميزانيـة التقديريـة: الموازنـات التقديريـة تعد إدارة لتوصيل

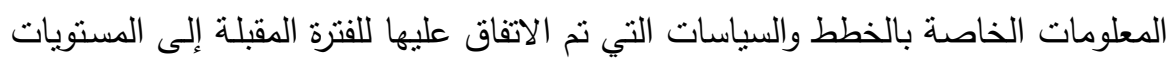

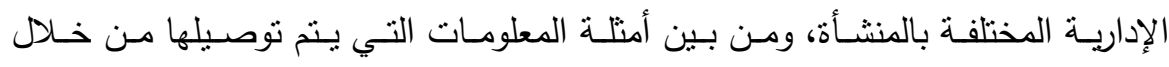

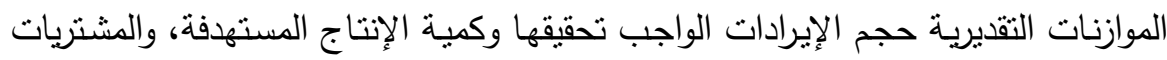
الازمة.... إلخ. - وظيفة التحفيز وعلاقتها بالميزانية التقديريـة: يمكن استخدام الموازنات التقديرية كوسيلة

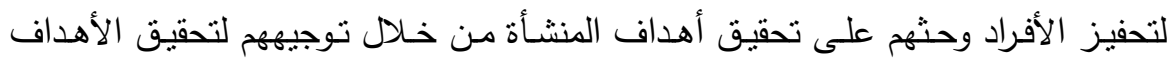

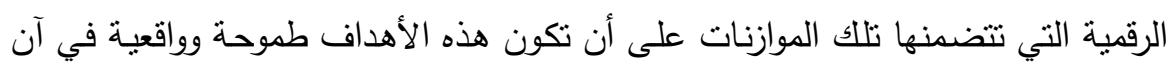

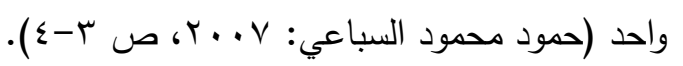

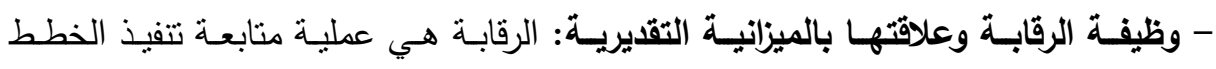
والأهداف الموضـوعة واستخدام المبزانيـات التقديريـة للرقابـة ويتحتم ضـرورة إبـلاغ الإدارة

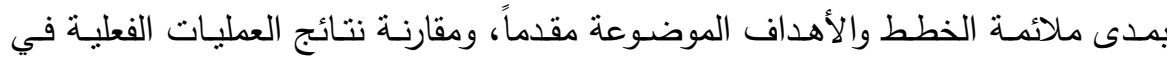
جميع اقسام المشروع بالخطط والأهداف الموضوعة مقدماً، ومتابعة الانحرافات التي تحدث نتيجة للتنفيذ الفعلي. - وظيفة تقييم الأداء: تستخدم مستويات الأداء الواردة بالموازنات التقديرية كأساس لتقييم أداء

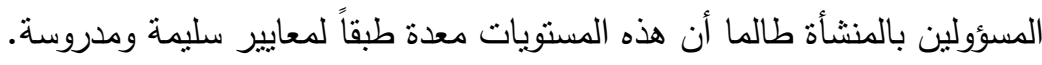


هذا ولا يمكن اعتبار هذه الوظائف مستقلة عن بعضها البعض إذ إنها تتداخل فيما بينها

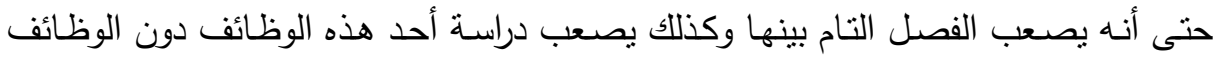
الأخرى فالتخطيط السليم يؤدي في حد ذاته إلى تتسيق بين الأهداف المختلفة والخطط الفرعية

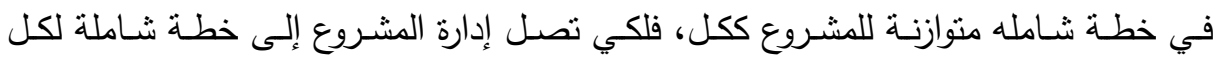

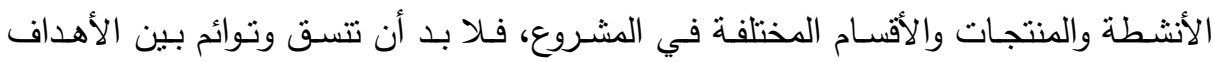

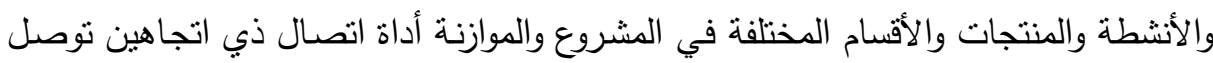
أهداف الإدارة العليا للمستويات الدنيا كما توصل الظروف الواقعية للأقسام ومدى قدرتها على التى

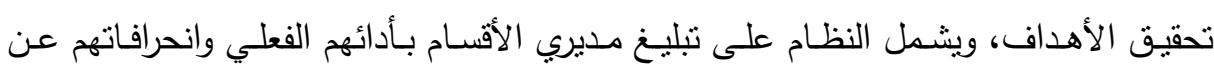
الموازنة وتوصيل أسباب الانحرافات عن طريق الرقابة، ولذلك نلاحظ أن هذه الوظئن الوائف رغم

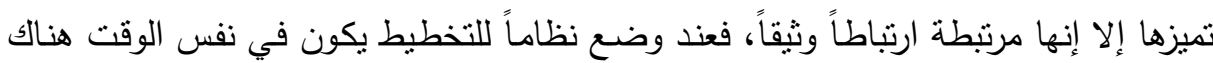

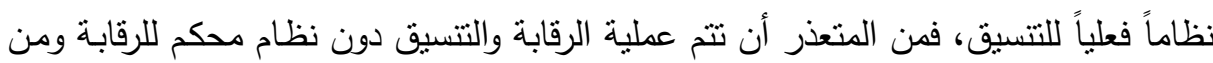

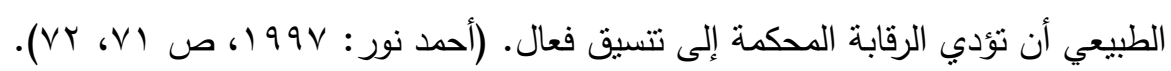

\section{إجباعاهت الدواسم}

$$
\text { 1 - متغيرات البحث }
$$

- المتغير التابع : الموقف التتافسي لشركات الملاحة الجوية. - المتغير المستقل : موازنة الأعباء البيئية.

Y - منهج الدراسة: تعتبر هذه الدراسة من نمط الدراسات الوصفية التحليلية والتي تعتمد علي المنهج الوصفي التحليلي والمنهج الاستقرائي لأجل: - مراجعة الدوريات العلمية والأبحاث السابقة. - مراجعة الدراسات النظرية السابقة في مجال الإدارة البيئية ونظم الإدارة البيئية الحديثة،

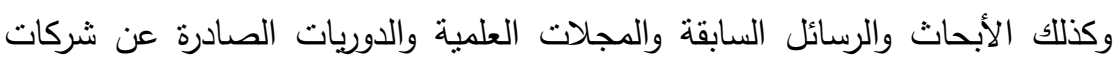

$$
\text { الملاحة الجوية. }
$$

- دراسات ميدانية ودراسة حالة وذلك بعمل مسح ميداني لثركات الملاحة الجوية.

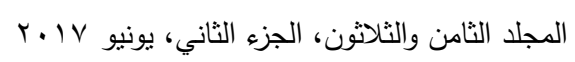




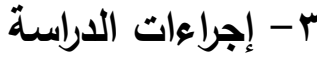

- جمع بيانات ومراجع مختلفة في مجال الدراسة. - استخدام وسائل جمع بيانات (استمارات استيان) تبرز المؤشرات البيئية الرئيسية التي ترتكز عليها الدراسة، ويمكن الاستعانة باستمارات استبيان محلية ودولية.

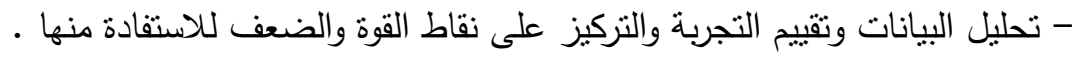

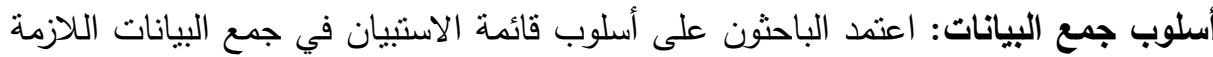
لاختبار فروض الدراسة حيث قام الباحثون بإعداد قائمة استبيان تتضمن: محاور الاستبيان: تتضمن الاسم، سنوات الخبرة ، القسم، المؤهل - الوظيفة - بيانات تم جمعها عن المشكلة موضوع الدراسة الميدانية مثل:

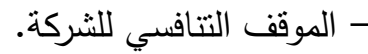
- استخدام موازنة الأعباء البيئية الدنضبطة وتحسين الموقف التنافسي في شركات الملاحة

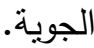
- استخدام موازنة الأعباء البيئية النقليدية وتحسين الموقف التنافسي في شركات الملاحة

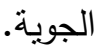

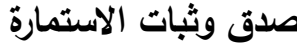
صدق الاتساق الداخلي لفقرات الاستيان:

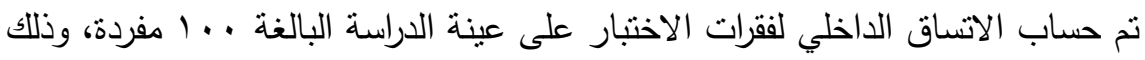

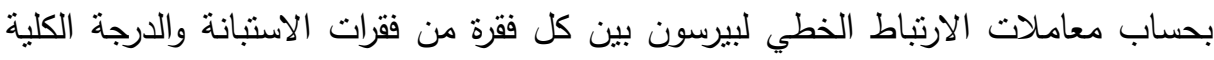
وقد كانت النتائج إيجابية بشكل عام، حيث دلت معاملات الارتباط المختلفة على وجود اتساق داخلي للفقرات، حيث تراوحت قيم معامل الارتباط بين

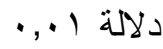
الثبات: أجرت الباحثة خطوات الثبات على العينة الاستطلاعية نفسها بطريقة التجزئة النصفية حيث تم إيجاد معامل ارتباط بيرسون بين درجات الأسئلة الفردية الرتبة ودرجات الأسئلة 
الزوجية الرتبة وقد نم تصحيح معاملات الارتباط فبلغ r ؟ ^, · وهذه قيمة ندل على ثبات عالي لمتلاستمارة.

\section{مجتمع وعينة الدراسة:}

مجتمع الاراسة: يتمنل مجتمع الدراسة في السادة العاملين بالسوق المالي.

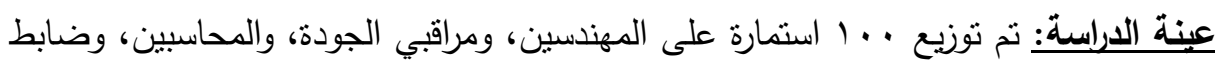
الاتصالات، والإداريين، القيادات في الادارات العليا ورؤساء الاقسام وتم استبعاد باد استمارة

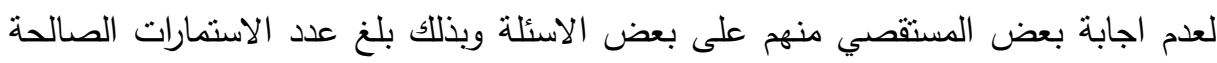

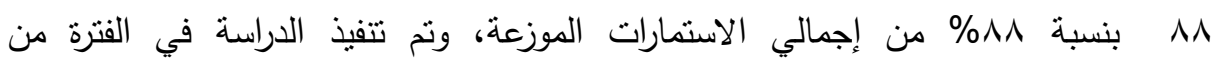

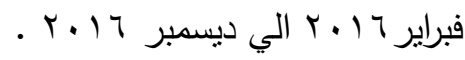
أساليب التحليل الإحصائي الإحصاءات الوصفية والتي من أمنلتها:

- جدولة البيانات في صورة جداول تكرارية (التكرار والنسبة المئوية) - إجراء بعض المقاييس الوصفية والتي كانت بالتحديد عبارة عن الوسط الحسابي المرجح

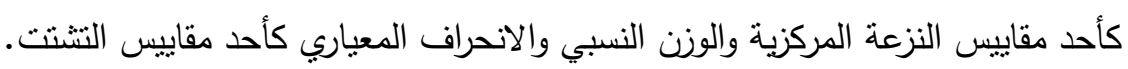

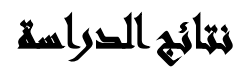

جدول(1): يوضح أراء عينة الدراسة في استخدام موازنة الأعباء البيئية التقليدية لتحسين الموقف التتافسي في شركات الملاحة الجوية

\begin{tabular}{|c|c|c|c|c|}
\hline الاتجاه & الاختلافل & المعياري & المتوسط & \\
\hline موافق & $1 \wedge, \Sigma$ & $\cdot, \mathrm{VV}$ & $\varepsilon, 1 \wedge$ & إدراج ميزانية خاصة بالبيئة فى الموازنة السنوية للثركة \\
\hline 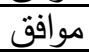 & Yr, & $\cdot, \wedge 0$ & $r, \wedge \uparrow$ & توفير المعدات ومستلزمات الصيانة في الثركة \\
\hline 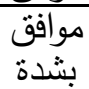 & $1 \wedge, \Gamma$ & $\cdot, \vee q$ & $\varepsilon, \mu r$ & دوريد اعنمادات مالية لفريق استثاري بيئي بالثركة بشكل \\
\hline احيانا & $r T, r$ & $\cdot, 90$ & $r, 1$. & تتوفر اعتمادات بيئية لاترقى لتحسين صورة الثركة \\
\hline موافق & $r, Y, V$ & $\cdot, \wedge 9$ & r,qr & دوري ومتاح لتكافة الثرار تقارير عن الحالة البيئية بشكل \\
\hline موافق & $r \cdot, r$ & $\cdot, 99$ & $\Gamma, 0 \wedge$ & أحتياجيات الثركة الثمات الخاصة بالبيئة تبعا لمستجدات \\
\hline
\end{tabular}

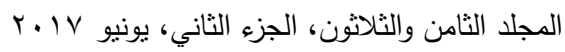


يتضح من بيانات الجدول السابق ان اغلبية عينة الدراسة نرى ان على الثركة إدراج

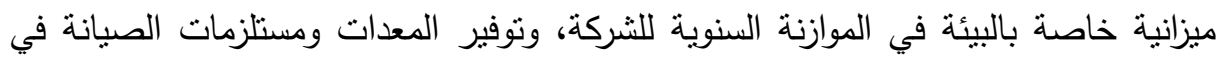
الشركة، حيث يوجد اعتمادات مالية لفريق اسنشاري بيئي بالثركة بشكل دوري، كما ترى باله

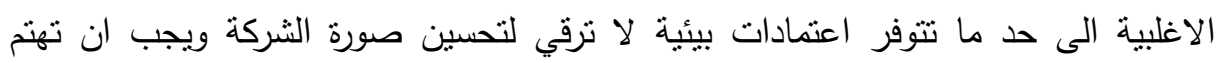

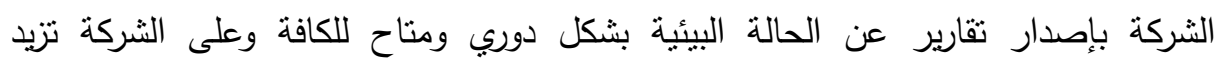
الاعتمادات الخاصة بالبيئة تبعا لمستجدات احتباجات الثركة. جدول(ץ): يوضح أراء عينة الدراسة في استخدام موازنة الأعباء البيئية المنضبطة وتحسين الموقف التتافسي في شركات الملاحة الجوية

\begin{tabular}{|c|c|c|c|c|}
\hline الاتجاه & الاختلافل & المعياري & المتوسط & \\
\hline بشَدة & $19, \pi$ & $\cdot, \wedge)$ & $\varepsilon, r$. & 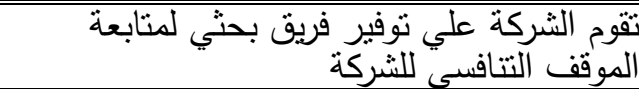 \\
\hline موافق & $r_{1}, \cdot$ & r, & T, q & البيئي لدمل الثركة علي وجود برامج لرفع الوعي \\
\hline موافق & $Y_{0, V}$ & $\cdot, 9 \wedge$ & $r, \wedge r$ & واضحة ومتاحة للجميع الارشادات البيئية في أماكن \\
\hline موافق & $r, r, r$ & $\cdot, \wedge \Gamma$ & $r, V T$ & للضهتم الثشركة بإناحة القرارات والبياتية. \\
\hline موافق & $r \varepsilon, \varepsilon$ & r & $r, v \wedge$ & 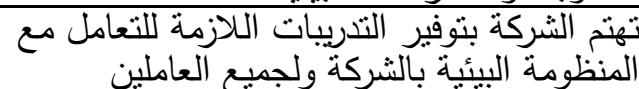 \\
\hline موافق & $1 \wedge, 7$ & $\cdot, V Y$ & $r, \wedge Y$ & دوريلن الثشركة بوضوح عن سياستها البيئية بشكل \\
\hline
\end{tabular}

يتضح من بيانات الجدول السابق، ان اغلبية عينة الدراسة ترى ان الثركة تقوم علي

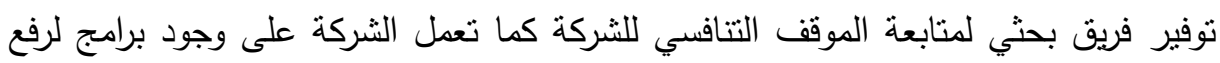
الوعي البيئي لاي العاملين بالثركة، كما تلتزم بوضع الارشادات البيئية في أماكن واضحة

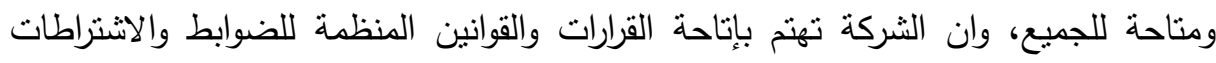
البيئية وتهنم بتوفير التدريبات اللازمة للتعامل مع المنظومة البيئية بالثركة ولجميع العاملين وان الثركة تعلن بوضوح عن سياستها البيئية بشكل دوري. لبهرئ 
جدول(ץ): يوضح أراء عينة الدراسة في الموقف النتافسي في شركات الملاحة الجوية

\begin{tabular}{|c|c|c|c|c|}
\hline الاتجاه & الاختلافل & 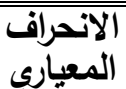 & المتوسط & \\
\hline 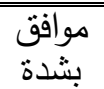 & IY, & $\cdot, \mathrm{OV}$ & $\varepsilon, 7$. & المماتُّة عالثركية بترتيب منقام بين الثركات \\
\hline موافق & 17, & $\cdot, 70$ & $\varepsilon, \cdot T$ & 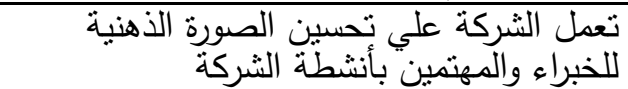 \\
\hline موافق & $r \wedge, r$ & $1, \cdot r$ & $\Gamma,\rceil \varepsilon$ & تعمل الشركة طبقا لمؤشرات عالمية ف منظومة \\
\hline موافق & $1 \wedge, 1$ & $\cdot, 71$ & $r, V T$ & 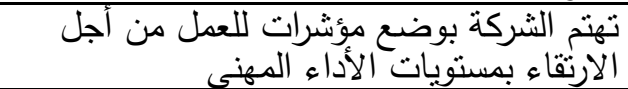 \\
\hline موافق & r & $\cdot, \wedge 9$ & $\Gamma, \vee \varepsilon$ & تلهنم الثركة بمتابعة الثقارير العالمية عن \\
\hline 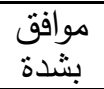 & $\pi, r$ & $\cdot, 0 \mathrm{~V}$ & $\varepsilon, Y \wedge$ & تبداخلها بشركلة بتحستيثر وتطوير منظومات العمل \\
\hline
\end{tabular}

يتضح من بيانات الجدول السابق، ان اغلبية عينة الدراسة نرى الثركة تحظي بترتيب منقدم

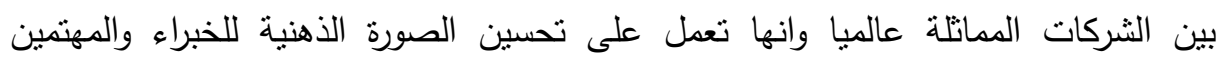
بأنشطة الشركة كما انها تهتم بوضع مؤشرات للعمل من أجل الارتقاء بمستويات الأداء المهني حيث انها تعمل طبقا لمؤشرات عالمية ف منظومة الجودة، وانها تهتم بمتابعة التقارير العالمية عن المنافسين في المجال وبتحديث وتطوير منظومات العمل بداخلها بشكل مستمر .

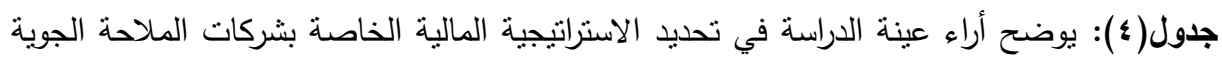
لابد ان تكون محددة وواضحة وتحقق الإدارة البيئية السليمة وتكون قصبرة الاجل

\begin{tabular}{|c|c|c|c|c|}
\hline الاتجاه & الاختلاف & المعياري & المتوسط & \\
\hline موافق & $r \cdot, \Lambda$ & $\cdot$, , & $\varepsilon, \cdot \wedge$ & المتعددة الاثار البيئية يؤثر على راس المال بأشكاله \\
\hline موافق & $r r_{,} \cdot 1$ & $\cdot, \wedge \vee$ & $\Gamma, q \varepsilon$ & توفيزٍ القرارات الهامة البيئية تعتبر دعم للإدارة في \\
\hline 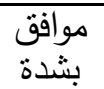 & 19,1 & ז • & $\varepsilon, r$. & 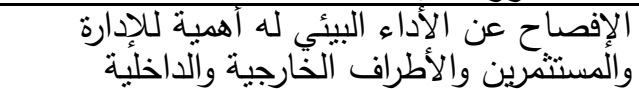 \\
\hline موافق & $r \Psi, O$ & $\cdot, 9 \leq$ & $\varepsilon, \cdots$ & 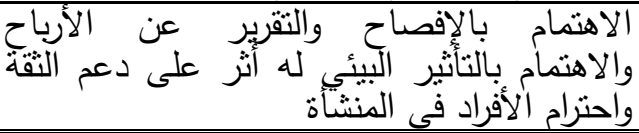 \\
\hline
\end{tabular}


يتضح من بيانات الجدول السابق، ان اغليية عينة الدراسة ترى قياس الاثار البيئية يؤثر

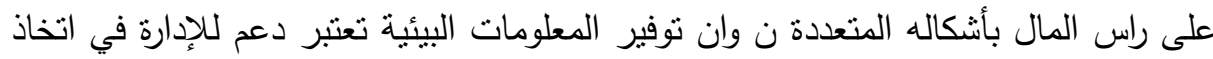

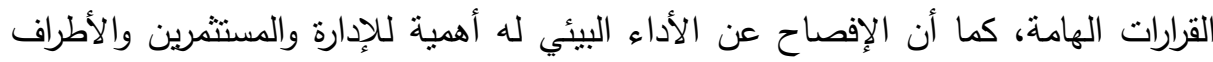

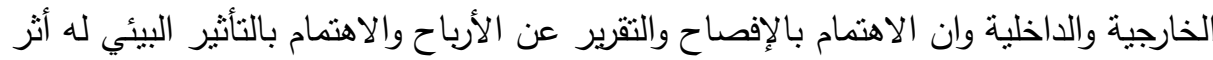
على دعم الثقة واحترام الأفراد في المنشأة. جلول(ه): يوضح أراء عينة الدراسة في يجب وضع الهن استراتيجية قابلة للنطبيق لنظم الإدارة

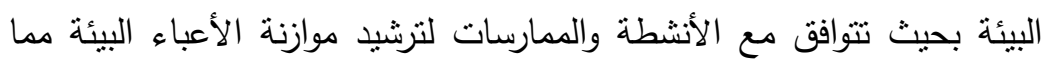

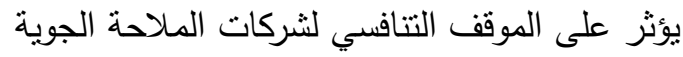

\begin{tabular}{|c|c|c|c|c|}
\hline الاتجاه & الاختلاف & المعياري & المتوسط & \\
\hline 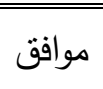 & $r 1,9$ & $\cdot, \wedge \vee$ & ५,१^ & للتطبيق لنظق التنافي لشّدارة البيئية الملاحة الجوية قابل \\
\hline احيانا & 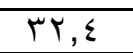 & $1, \cdot 1$ & $r, I r$ & الموقف التنافسي لثركات الملاحة الجوية قوى \\
\hline موافق & $19, \pi$ & $\cdot, \vee \vee q$ & «,, . & 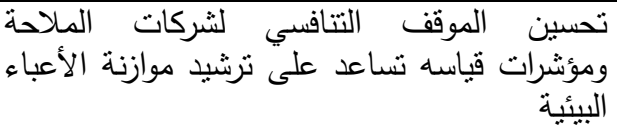 \\
\hline
\end{tabular}

يتضح من بيانات الجدول السابق، ان اغلبية عينة الدراسة ترى ان الموقف التتافسي لشركات الملاحة الجوية قابل للنطبيق لنظم الإدارة البيئية وان الموقف التتافسي لثركات الملاحة الجوية قوى وان تحسين الموقف التتافسي لثركات الملاحة ومؤشرات قياسه تساعد على ترشيد موازنة الأعباء البيئية.

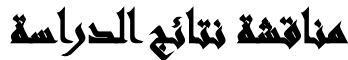

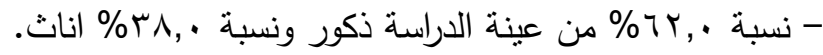

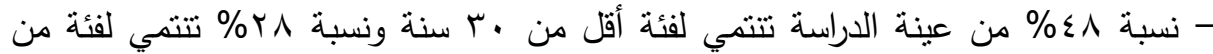

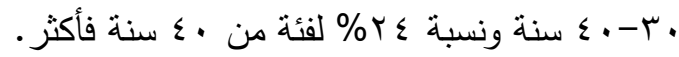
- نسبة ro من عينة الدراسة من الحاصلين على البكالوريوس ونسبة بr\% من من الحاصلين على ماجستير ونسبة rr\% من الحاصلين على دكتوراه. 


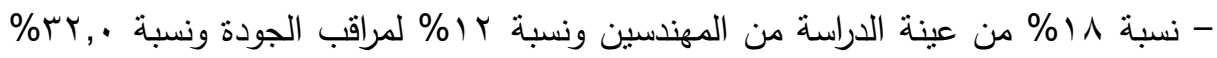
للمحاسب ونسبة ؛ (\%

ترى الثركة تحظي بترتيب متقدم بين الشركات المماتلة عالميا وانها تعمل على تحسين لضابط الاتصالات ونسبة \& ب \% للإداري. - أغلبية عينة الدراسة ترى ان على الثركة إدراج ميزانية خاصة بالبيئة في الموازنة السنوية للثركة، وتوفير المعدات ومستلزمات الصيانة في الثركة، حيث يوجد اعتمادات مالية لفريق استشاري بيئي بالثركة بشكل دوري، كما ترى الاغلبية الى حد ما نتوفر اعتمادات

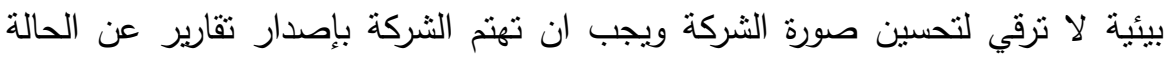
البيئية بشكل دوري ومتاح للكافة وعلى الثركة تزيد الاعتمادات الخاصة بالبيئة تبعا

$$
\text { لمستجدات احتباجات الثركة. }
$$

- أغلبية عينة الدراسة نرى ان الثركة تقوم علي توفير فريق بحثي لمتابعة الموقف التتافسي

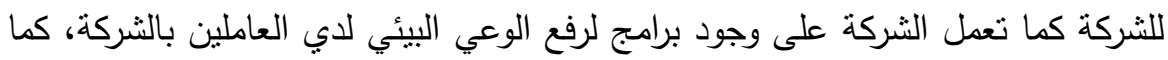

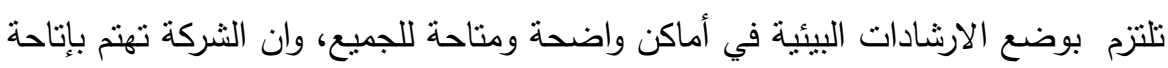
القرارات والقوانين المنظمة للضوابط والاشتراطات البيئية وتهتم بتوفير التدريبات اللازمة

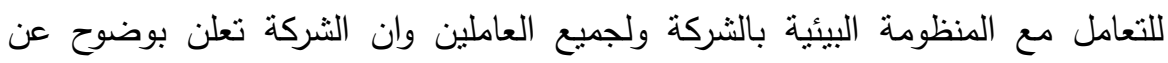
سياستها البيئية بشكل دوري.

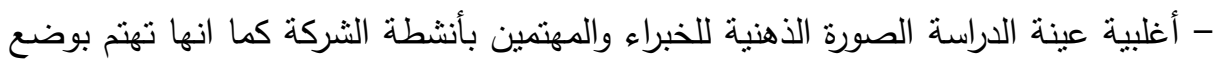
مؤشرات للعمل من أجل الارتقاء بمستويات الأداء المهني حيث انها تعمل طبقا لمؤشرات عالمية ف منظومة الجودة، وانها تهنم بمتابعة الثقارير العالمية عن المنافسين في المجاء الهال وبتحديث وتطوير منظومات العمل بداخلها بشكل مستمر .

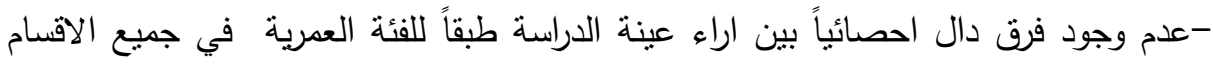
مما يدل على تقارب آرائهم في حين يوجد فرق بينهم في استخدام موازنة الأعباء البيئية المنضبطة وتحسين الموقف التنافسي في شركات الملاحة الجوية والموقف التنافسي في شركات الملاحة الجوية.

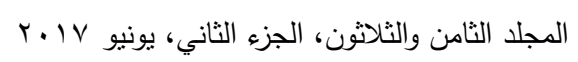


- وجود فرق بين اراء الفئة العمرية من (•r-•ـ سنة ) وكلا من الفئتين العمريتين (اقل من

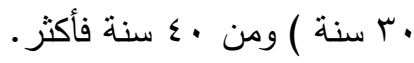

-عدم وجود فرق دال احصائياً بين اراء عينة الدراسة طبقاً للمؤهل في جميع الاقسام مما يدل على تقارب آرائهم في حين يوجد فرق بينهم في استخدام الموقف التتافسي في شركات

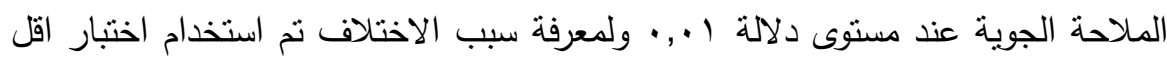
فرق معنوي الجدول النالي يوضح ذلك. - وجود فرق بين آراء الحاصلين على البكالوريوس والحاصلين على الدكتوراه

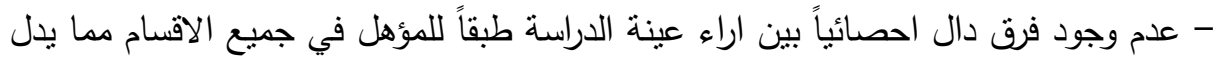

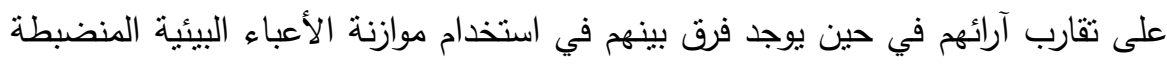
وتحسين الموقف التنافسي في شركات الملاحة الجوية و ان تحديد الاستراتيجية المالية الخاصة بشركات الملاحة الجوية لابد ان تكون محددة وواضحة وتحقق الإدارة البيئية السليمة وتكون قصيرة الاجل ودور الدولة في تدعيم القدرات التتافسية لثركات الملاحة الجوية .

استخدام موازنة الأعباء البيئية المنضبطة وتحسين الموقف التتافسي في شركات الملاحة الجوية - وجود فرق بين آراء الاداري وبين كلا من مراقب الجودة وضابط الاتصال

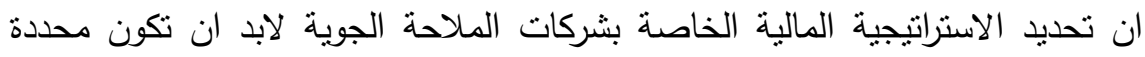

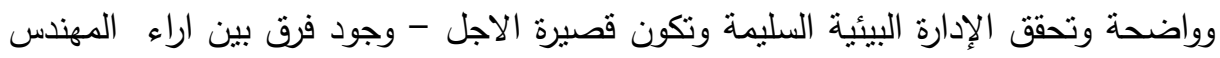
وكلا من اراء مراقب الجودة والمحاسب وضابط الاتصال والاداري. دور الدولة في تدعيم القدرات التتافسية لثركات الملاحة الجوية - وجود فرق بين اراء مراقب الجودة وكلا المحاسب وضابط الاتصال ورأي المحاسب وكلا من مراقب الجودة

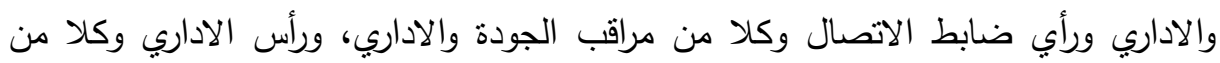
المحاسب وضابط الاتصال. 
اختبار صحة فروض الاراسة:

اختبار صحة الفرض الاول: توجد علاقة ارتباطية بين استخدام موازنة الأعباء البيئية التقليدية

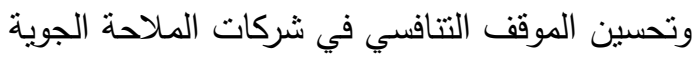

لاختبار فرض الدراسة قام الباحث باستخدام معامل الارتباط البسيط ومعامل الانحدار البسيط - المتغير التابع: الموقف التتافسي لثركات الملاحة الجوية. - المتغير المستقل: موازنة الأعباء البيئية التقليدية تشير البيانات الى معنوية نموذج الانحدار وذلك عند مستوى دلالة ا.,., وان

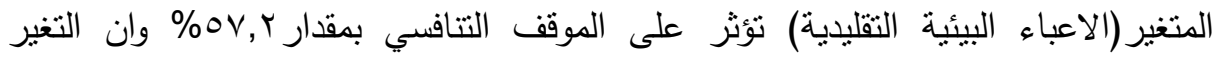
الحادث في الموقف التنافسي بمقدار الوحدة يسببه التغير في الاعباء البيئية التقليدية

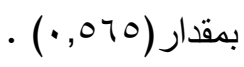

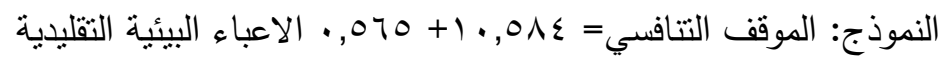
اختبار صحة فرض الدراسة الثاني: توجد علاقة ارتباطية بين استخدام موازنة الأعباء البيئية

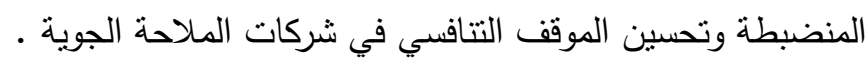
لاختبار فرض الدراسة قام الباحث باستخدام معامل الارتباط البسيط ومعامل الانحدار البسيط - المتغير التابع: الموقف التتافسي لشركات الملاحة الجوية. -المتغير المستقل: موازنة الأعباء البيئية المنضبطة.

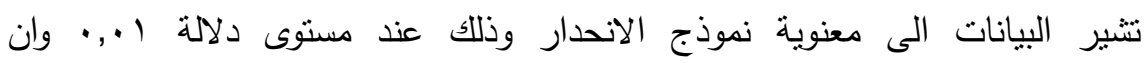

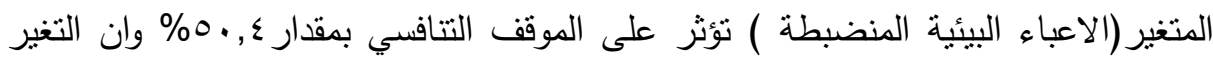
الحادث في الموقف التتافسي بمقدار الوحدة يسببه التغير في الاعباء البيئية المنضبطة

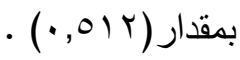

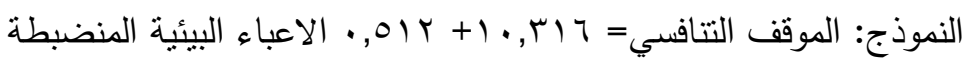
اختبار صحة الفرض الثالث: نوجد علاقة ارتباطية بين دور الدولة في تدعيم قدرات شركات الملاحة الجوية وتحسين الموقف التتافسي لها 
لاختبار فرض الدراسة قام الباحث باستخدام معامل الارتباط البسيط ومعامل الانحدار البسيط

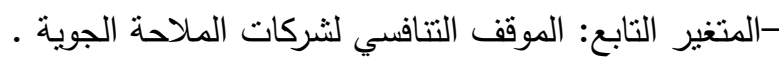
- المتغير المستقل: موازنة الأعباء البيئية التقليدية

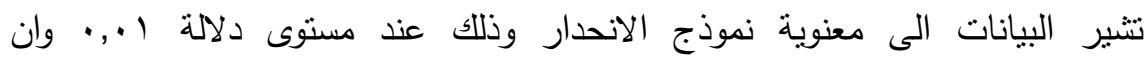

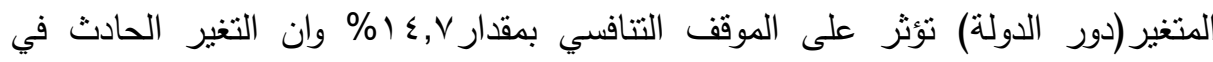

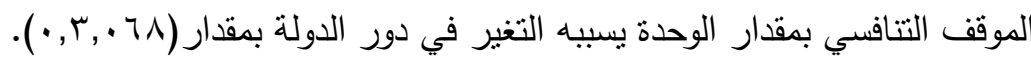

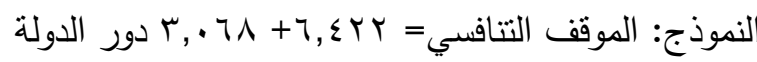
أثر المتغيرات معا على الموقف التنافسي: تشير البيانات الى معنوية نموذج الانحدار وذللك

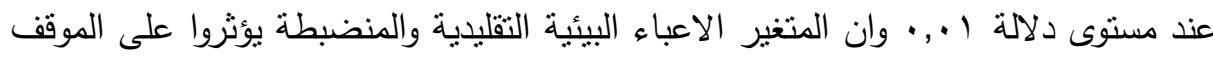
التنافسي ب مقدارع, آج\% وان التغير الحادث في الموقف التتافسي بمقدار الوحدة يسببه

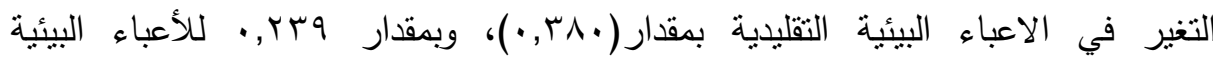
المنضبطة، وان أثر الدولة اختفى في ظل المتغيرين الاخرين لقوتهما. النموذج:

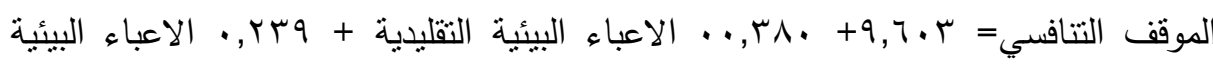
المنضبطة.

\section{تمصيايت للفواسمة}

- تطوير طرق قياس وإدارة المخاطر البيئية لدعم الموقف التتافسي للنشركة. - زيادة درجة الثفافية بالنسبة للمخاطر التي تتعرض لها الثركة، ويجب أن تتاح المعلومات الكافية وفي الوقت المناسب للمتعاملين معها لضمان ترشيد تللك الأعباء لاعم موقف 


\section{مرائ الصواسة}

أحمد نور(99v (1)): المحاسبة الإدارية واتخاذ القرارات وبحوث العمليات، دار الجامعية للنشر

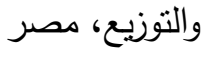

جمال سعد خطاب( ( ץ): "دراسات فى محاسبة التكاليف البيئية"، مطبعة السلام، القاهرة

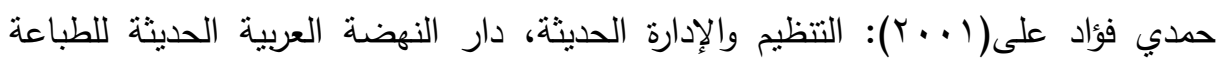
والنشر ، بيروت

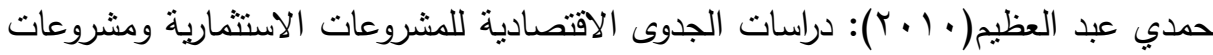

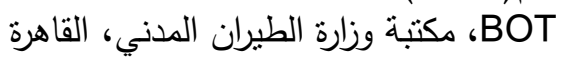

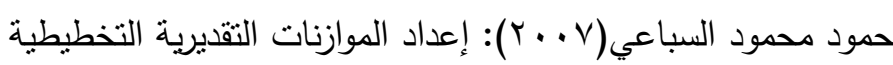

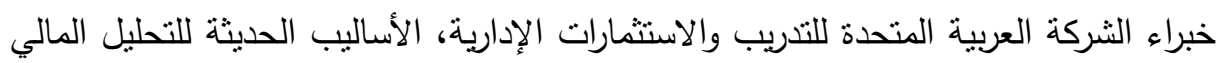
وإعداد الموازنات لأغراض التخطيط والرقابة، ؟ ؟ . Y.

خيرت ضيف(991 (19): الميزانية التقديرية، دار النهضة العربية للطباعة والنشر ، القاهرة ماهر عبد الوهاب سيف قطب(9 ج . r): الإدارة البيئية ودورها في اتخاذ قرارات التوافق البيئي،

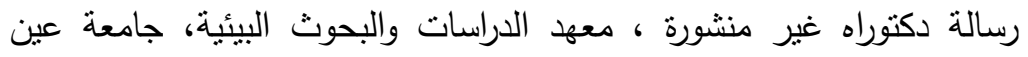

شمس

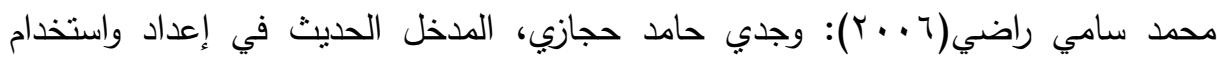
الموازنات، الدار الجامعية، مصري هامر ولهر

محمد سامي راضي، وجدي حامد حجازي(؟ × . †): المدخل الحديث في إعداد واستخدام

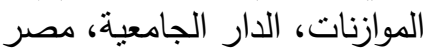

محمد صالح الحناوي(ץ . . ץ): الإدارة المالية والتمويل، دار الكتاب الجامعي، الإسكندرية

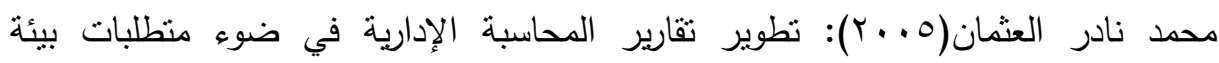

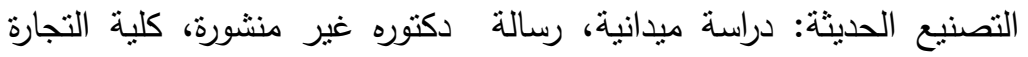

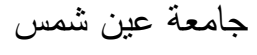

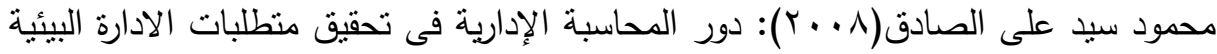

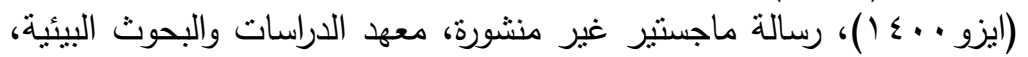

جامعة عين شمس ، رس 


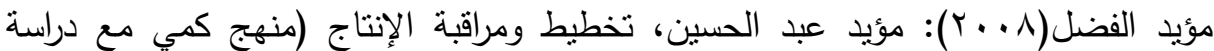

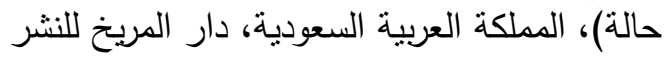

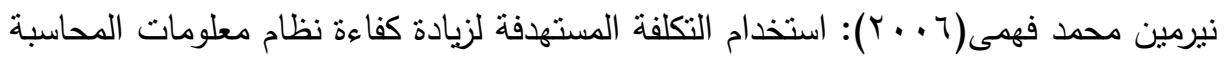

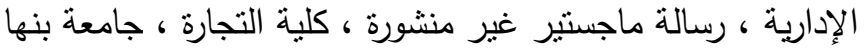

وديع محمد عدنان( ( . ب): "محددات القدرة التتافسية للأقطار العربية في الأسواق الدولية، بحوث ومناقشات"، تونس

Demery R., and Others, "Getting Started with Environmental Cost Accounting", Environmental Quality Management, Vol., 8, Autumn, 2014.

Emblemsvag and Bras, 2001.

Graciela Marı'a Scavone, Challenges in internal environmental management reporting in Argentina ,Argentina Sustentable A.C., Buenos Aires, Argentina,2006

Robert Gale, Environmental management accounting as a reflexive modernization strategy in cleaner production, Journal of Cleaner Production, vol 14, 2012.

Wilsmore ,A ,wcc, business budgets and budgetary controle, London, sirisaac pitman and sonsitd, 1999 
طارق عبد العال حماد وآخرون

\title{
A PROPSED PROGRAM TO NATIONALIZE ENVIRONMENTAL BUDGET BURDENS AND ITS IMPLICATIONS ON THE COMPETITIVE POSITION OF SOME AIR NAVIGATION COMPANIES
}

\author{
Hamad, T. A. ${ }^{(1)}$; khatab,G. S. ${ }^{(1)}$; Elsayed, A. A. ${ }^{(2)}$ and Farid, M. A. \\ 1) Faculty of Commerce, Ain Shams University 2) National Air \\ Navigation Services Company
}

\begin{abstract}
The improvement of the environmental performance of aviation challenge takes the International Civil Aviation Organization seriously. In fulfilling its responsibilities, the organization has developed a set of standards, policies and guidance material for the application of integrated measures to address aircraft emissions, engine noise adoption of technological improvements, operating procedures, and proper organization of air traffic, the appropriate airport and land-use planning, and the use of existing options on the market, the study aimed to access the program a proposal to streamline the environmental burdens the budget and the implications on the competitive position of some of the air navigation companies, and adopted a researcher on the descriptive and analytical approach to extrapolate the study population, and which consisted of 100 single workers connect to engineer, technical, and administrative the study found the presence of correlation between the use of traditional environmental burdens budget and improve the competitive position of the air navigation companies, and the existence of a correlation between the use of environmental burdens balancing disciplined and improve the competitive position of the air navigation companies, the study recommended an increase of the degree of transparency for the risks to the company, should be sufficient information is available in a timely manner to customers with them to
\end{abstract}

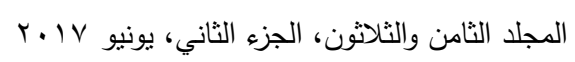


مجلة العلوم البيئية

معهد الدراسات والبحوث البيئية - جامعة عين شمس لبه

ensure the rationalization of those burden to support the company's position. 